Article

\title{
Function-Based and Multi-Scale Approach to Green Roof Guidelines for Urban Sustainability Transitions: The Case of Bogota
}

\author{
R. Andrés Ibáñez Gutiérrez ${ }^{1, *}$ and Mónica Ramos-Mejía ${ }^{2}$ (D) \\ 1 Department of Architecture, Pontificia Universidad Javeriana, Bogota 110111, Colombia \\ 2 Department of Management, Pontificia Universidad Javeriana, Bogota 110231, Colombia; \\ ramosm.monica@javeriana.edu.co \\ * Correspondence: ra.ibanezg@javeriana.edu.co; Tel.: +57-350-261-9330
}

Received: 1 June 2019; Accepted: 20 June 2019; Published: 22 June 2019

check for updates

\begin{abstract}
A growing number of local green roof niches across the globe are transitioning into the mainstream domain. Guidelines are key to this process, as they define technological environments and set the criteria for best practices in a given socio-technical setting. Although the German Forschungsgesellschaft Landschaftsentwicklung Landschaftsbau (FLL) cornerstone guidelines provided solid empirical ground and established technical parameters for the successful application of green roofs across continents, investigations about alternative green roof guidelines for emerging markets remain very scarce. The paper presents the inclusive approach followed by the Bogota Green Roof Guidelines, which were the result of a multi-actor participatory process that examined how to embrace a wide range of emerging green roof technologies and local adaptations while promoting quality of application at different scales, regardless of the system used, and despite the absence of local robust empirical data on performance parameters. As a result, Bogota's Green Roof Guidelines incorporated ad hoc elements: (1) new definitions and taxonomy, (2) function-based contents, (3) multi-scale approach, and (4) performance scoping. These aspects are discussed to provide novel insights for the advancement of green infrastructure policies in diverse institutional settings aiming to promote quality and simultaneously support markets that make room for a wide variety of green infrastructure practices.
\end{abstract}

Keywords: green roof guidelines; vegetated roofs; green roofs; biotic roofs; green infrastructure; function-based guidelines; multi-scale guidelines; sustainability transitions; socio-technical niches; ecoproductive architecture

\section{Introduction}

According to United Nations' (UN) urbanization projections, by 2030 the number of megacities with a population of more than 10 million is projected to be 43 , most of them located in developing regions. The combination of high population density, poverty, and limited resources makes the megacities of the developing world a significant sustainability challenge [1]. Green buildings have been considered as a suitable socio-technical innovation to reduce the environmental and natural resource footprints of growing cities [2]. Moreover, in the recent body of knowledge on net positive development and design, man-made infrastructure and ecoproductive architecture are considered as sources of environmental contributions that can afford to augment the overall integrity and resilience of both anthropogenic and natural ecosystems that support life and foster well-being in urban settings [3]. Green roofs are among the most effective green-building technologies to mitigate negative impacts caused by urbanization, but to also restore the capacity of cities to produce environmental contributions [4-7]. 
Roofs cover large surfaces of the urban canopy in megacities [6]. These vast grey areas cause urban environmental problems like temperature rise, excess of stormwater runoff, pressure to storm water collection systems, and biodiversity loss. However, they also represent a potential for developing resilient cities by acting as a physical platform to increase the amount of vegetated cover on building surfaces that otherwise would remain underused. Scholars have found sufficient evidence of the economic, social, and environmental benefits generated by vegetated roofs and other types of urban green infrastructure incorporated onto the built footprint of cities [5,7-9].

Latin America and North America are the most urban mega regions in the world. By 2050, $90 \%$ of the Latin American population is expected to live in urban areas [1]. With more than 8 million people, Bogota is expected to share a place in the list of Latin American megacities by 2030 with Rio de Janeiro, São Paulo, Mexico City, Lima, and Buenos Aires. The population growth animated by vibrant economic activity and the massive exodus from rural areas has expanded the grey fabric in Bogota, which now occupies more than two-thirds of the land [3], leaving little room for green and pervious surfaces at ground level. A decade ago, green roofs began to stand out as a promising practice that helps alleviate the lack of green surfaces and contributes to solving most of the major environmental problems in Bogota. General interest in green roofs began in 2009 upon the former empirical studies conducted at National University of Colombia, which determined the basic technical parameters for the application of green roofs in the local context [3]. These studies were key for the green roof technologies to gain building designers and developers' attention and trust. Since then and to this day, the development of a green roof niche has created an action platform where a network of multiple actors can aspire to shape together a healthier urban environment in Bogota [3].

Recent literature has argued that the role of socio-technological innovation in the developing world is not only about becoming more resource-efficient, but also about reconfiguring the power balance within production-consumption systems [10]. Formal and informal institutions in the developing world are contested and personalized at various extents, undermining the well-being of many and strengthening the privileges of a few, and therefore, reproducing patterns of social exclusion (p. 217). In these contexts, socio-technical niche development processes should pay special attention not to reproduce such patterns. In the case of Bogota's green roof niche, this implies that policies and guidelines in niche formation stages should stem from the interplay and participation of local actors, which is closer to a stewardship instrument than to a ruling norm.

Socio-technical niches are protected (and often marginal) market areas where juvenile innovations can be tested and adjusted before facing the open market [11,12]. The formation of "green" niches, that is, resource-efficient innovations that nurture systems of provision, has proven to be strategic in transforming systems of production and consumption into more sustainable ones [11]. This transformation processes at the system level have been called sustainability transitions [13]. Under these optics, in which ways could green roof guidelines in the context of developing niches be formulated to include a number of different technologies, local adaptations, innovations, and further developments?

Bogota's green roof niche is among the fastest growing in Latin America. This paper studies the socio-technical niche of green roofs in Bogota, Colombia. Specifically, it looks at the development of the city's official green roof guidelines [14], as a key element to systematize new knowledge and capabilities [15], in order to promote and strengthen practices within the niche. We will argue that these guidelines have strengthened the green infrastructure practice in the megacity of Bogota, opening up a pathway for urban sustainability transitions. By the time the green roof niche started to gain momentum, three bylaws envisioned Bogota's green infrastructure future: the policy on eco-urbanism and sustainable construction from 2014 to 2024 (Bylaw 566), the green building recognition program (Bylaw 3654), and the roof greening guidelines (Bylaw 418). In response to the latter, the Secretary of Environment of the city published the Official Green Roof Technical Guidelines (BBRG) to promote and regulate the practice [14]. Even though these guidelines were linked to the official Sustainable Building Standard, Bylaw 418 states that they are aimed at promoting sustainable architectural technologies, rather than being compulsory. These guidelines incorporated their own distinctive elements to 
meet local challenges after a participatory formulation process. These distinctive features include (1) function-based contents, (2) multi-scale approach, (3) performance scoping, and (4) new definitions and taxonomy. These four aspects ended up being distinct when contrasting the Colombian guidelines with the most influential German FLL guidelines, "Guidelines for the Planning, Construction and Maintenance of Green Roofing", commonly referred to as the German FLL Guidelines for green roofs [4-6,16-18].

This paper is structured as follows. Section 2 elaborates on the different stages that the formulation of the BBRG underwent, the actors involved, the issues stemming from the disagreements found among them, and finally, how a consensus was reached via the distinctive aspects proposed in the BBRG. Section 3 presents a summarized description of the resulting ad hoc BBRG and their distinctive aspects. Section 4 examines, under the perspective of sustainability transitions, the implications of the BBRG's proposed contents for the advancement of green roof guidelines in emerging niches, non-temperate climates, and developing countries displaying a lack of extensive empirical studies and ambivalent (formal and informal) institutional settings. Section 5 highlights the key insights that the BBRG's outcome and their formulation process brought about for the advancement of guidelines worldwide and suggests further research areas.

\section{Methodology: Formulation Process of the Bogota Biotic Roof Guidelines}

The formulation of the BBRG underwent four stages: literature review, discussion with government officials, multi-actor involvement, and consensus. The literature review compared the key technical documents to date in Europe, North America, Asia, and Latin America, and the former empirical studies on green roofs conducted at National University of Colombia [19-27]. It was found that the German FLL guidelines had directly and indirectly influenced all of the above references by adopting a lexicon, best practices criteria, or quantitative performance parameters, in most cases regardless of the local climate, socio-technical domains, and institutional settings. A summary of the common lexicon and technical parameters found in the literature was then presented to local government authorities of the Sub-direction of Eco Urbanism of the Secretary of Environment of Bogota who favored the rigorous and precise set of parameters stemming from the FLL, but argued that these parameters could not be transferred to non-temperate locations like Bogota's without carefully considering the particular local conditions. The authorities also noted the prolific in-depth empirical investigations that supported the decision-making in Germany over four decades before arriving at quantitative baselines and standards $[6,8,17,18]$. This led to questions on how those parameters could be set in Bogota in the absence of extensive empirical evidence and in-depth studies of every single parameter to be addressed by the BBRG.

After these two preliminary stages, the main structure and contents of the guidelines that had been reviewed were then presented to a multi-actor table with representatives from the local government, the building industry, green roof contractors, designers, and environmentalists. Several meetings with the abovementioned stakeholders and open to the general public were held during the formulation process to listen to their feedback and opinions. Soon after the first encounters, it became evident that the reviewed guidelines would not include all the technologies available in Bogota at that time, and would favor the use of certain types of green roof systems without considering the particular regional context and the actual capabilities of the whole local supply chain of green roofs. The number of issues stemming from the open discussion motivated alternative approaches and set a new roadmap for the BBRG.

The BBRG's formulation process experienced a number of challenges and questions that this type of instrument must face in the emerging green-roof markets and in developing countries in general. On the other hand, some of these localized challenges also encompassed relevant issues of sustainability that all countries and settings are currently concerned about. Some of the questions suggested by participants included the following: How can niches contribute to guidelines without solid studies that can accurately validate performance in developing countries?, how can future guidelines and 
revisions to the current ones include the technologies, adaptations, and user-made solutions that were not conceived and presented in the state-of-the-art section of the most well-known guidelines?, how can a lexicon used by guidelines contribute to a better understanding of the technology?

The BBRG's aim was to build understanding of the functional principles of green roofs in the Colombian context. All actors involved paid special attention to creating a generic language that prevented favoring a particular technology. A lexicon that could address these concerns was considered the key underpinning of the guidelines. The new definitions and classifications were agreed upon based on differential scale performance, performance of components, and the main purpose of the overall biotic roof (see Section 3.4).

The different voices were gathered in meeting minutes and received in official written letters sent by the participants. These opinions were then analyzed to identify the ones that best represented the interests of the majority of the people involved in the process. Then, an ideation process by one of the authors took place in the form of a brainstorm to consider alternative ways to structure the guidelines and their contents. These alternatives were presented to government officials and to the members of the technical table. The function-based and multi-scale approach stood out as the one that would lead to a common agreement. Following the consensus on the spirit and structure of the guidelines, the detailed writing process started. After a process of feedback and adjustments to the detailed contents, a final open event was held to officially launch the guidelines.

\section{Result: The Bogota Biotic Roof Guidelines}

Several authors have found a correlation between the higher number of implemented green roofs and walls in specific regions and the existence of policy instruments and guidance tools, in comparison to local environments where the latter do not exist and which display a lower number of implementations [28]. This is partly due to the fact that guidelines build understanding of the technology, which creates capabilities to overcome uncertainties and myths associated with a niche practice [29]. Lack of knowledge and proper understanding of the set of physical components of a socio-technical system results in failures that slow down or constrain the growth of a given practice-in this case, green roofs [18]. In 2010, the Secretary of Environment of Bogota aimed to promote and regulate the application of green roofs in the city as an effective and sustainable strategy that used the existing building footprint to improve environmental quality affected by the urbanization process. The main targets were combating the low air quality caused by high concentrations of particulate matter, noise, the flood risk due to surface runoff, the urban heat island effect, and biodiversity loss [3]. Since the publication of the BBRG until 2016, the number of green roof projects in Bogota has been estimated at 131, which accounts for an area of $60,778 \mathrm{~m}^{2}$ [30].

To meet this aspiration, the guidelines set the technical requirements and recommendations to ensure quality standards and correct functioning of this type of roof in Bogota. Although the most advanced standards and guidelines worldwide were considered, the final outcome provided technical directions conceived to address the local economic, social, and environmental conditions of Bogota, which resulted in an ad hoc approach that incorporated distinctive aspects.

Most of the existing guidelines worldwide are component- and layer-based, that is, waterproof membrane, root barrier, among other elements. Instead, the BBRG present technical advice, features, and performance requirements pertaining to the functions that are decisive in guaranteeing the optimal operation of green roofs in Bogota, despite the type of technology or system applied. This inclusive approach was adopted as a measure to promote the diversity of existing technologies, but also to provide room for future developments and local adaptations, as long as they comply with the established technical parameters.

In terms of their ruling nature and scope, the BBRG pursue a dual purpose: disseminating the general basic knowledge related to the correct functioning of green roof systems and setting prescriptive parameters needed for an extended best practice throughout the city. Thus, the BBRG's contents elaborate on (1) the minimum compulsory requirements for all green roof cases in Bogota with regard to 
their basic functions, regardless of the type of system, and (2) the suggested technical recommendations to achieve optimal performance related to the most widespread technologies, codes, and standards in the international arena.

The BBRG establish basic requirements on four scales: (1) the typical section of the technology used (microscale), (2) the adaptation of the biotic roof system on a specific roof (mesoscale), (3) the overall building (macroscale), and 4) the ecological network the biotic roof belongs to (metascale).

The BBRG embrace five stages of the lifecycle of a biotic roof: (1) specifications and design, (2) preparation, (3) installation, (4) maintenance and follow-up, and (5) disassembly.

In addition to the minimum requirements on four scales, the BBRG outline two other scopes of performance: advanced performance for outstanding best practice and special performance associated with urban environmental resilience and ecoproductivity (generation of environmental contributions) [31].

\subsection{Function-Based Contents}

The majority of the existing green roof guidelines follow a component-based approach $[5,6,8,17,18]$, which allows for rigorous determination of properties and technical parameters. However, this approach excludes several technologies that have components not considered in the guidelines (Figure 1). The BBRG's function-based structure aimed to provide inclusive technical criteria for any kind of system technology, including local adaptations and new developments. To meet this goal, the performance of green roofs in Bogota was linked to basic functional principles aimed for by different components. A matrix of the most common stable and active components relates them to six functions at the technology scale: watertightness, drainage, water retention, robustness, nutrition, and filtration. The guidelines determined the minimum requirements pertaining to the operational capacity of a biotic roof system at different scales (Figure 2).

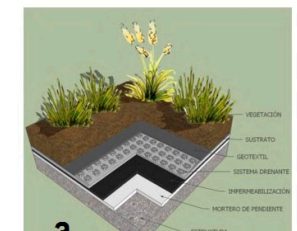

a.

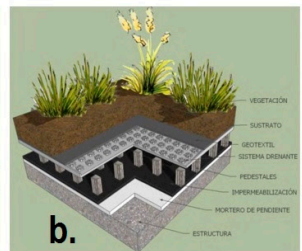

b.

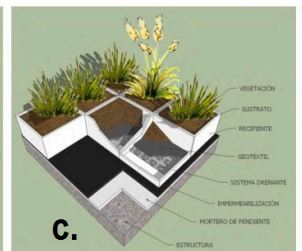

c.
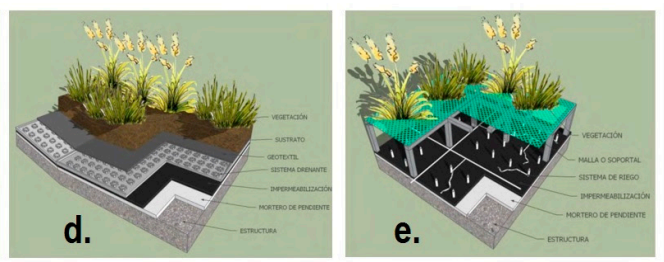

Figure 1. Participants presented diverse technologies, which were considered throughout the Official Green Roof Technical Guidelines' (BBRG) formulation process. (a) Multilayered system; (b) Elevated system; (c) Modular system; (d) Mono-layered system; (e) Aeroponics system.

The contents of every function were organized into five headings to facilitate understanding and address different useful information: (1) purpose, which helps understand the performance goals; (2) key aspects, which elaborate on the factors that are decisive in reaching the performance goals; (3) requirements, which set mandatory qualitative and quantitative performance ranges to comply with, regardless of the green roof system used; (4) properties and units, which help designers and supervisors identify the calculations to be done and the assessment criteria; and (5) recommendations, which are non-mandatory suggestions aimed at achieving outstanding performance (Figure 3). This organization reflects the dual purpose of the guidelines, namely, prescription and guidance. Additionally, it allows all actors, independently from their technical level, to use the guidelines. 
BOGOTA GREEN ROOF GUIDELINES

FUNCTION-BASED AND MULTI-SCALE APPROACH

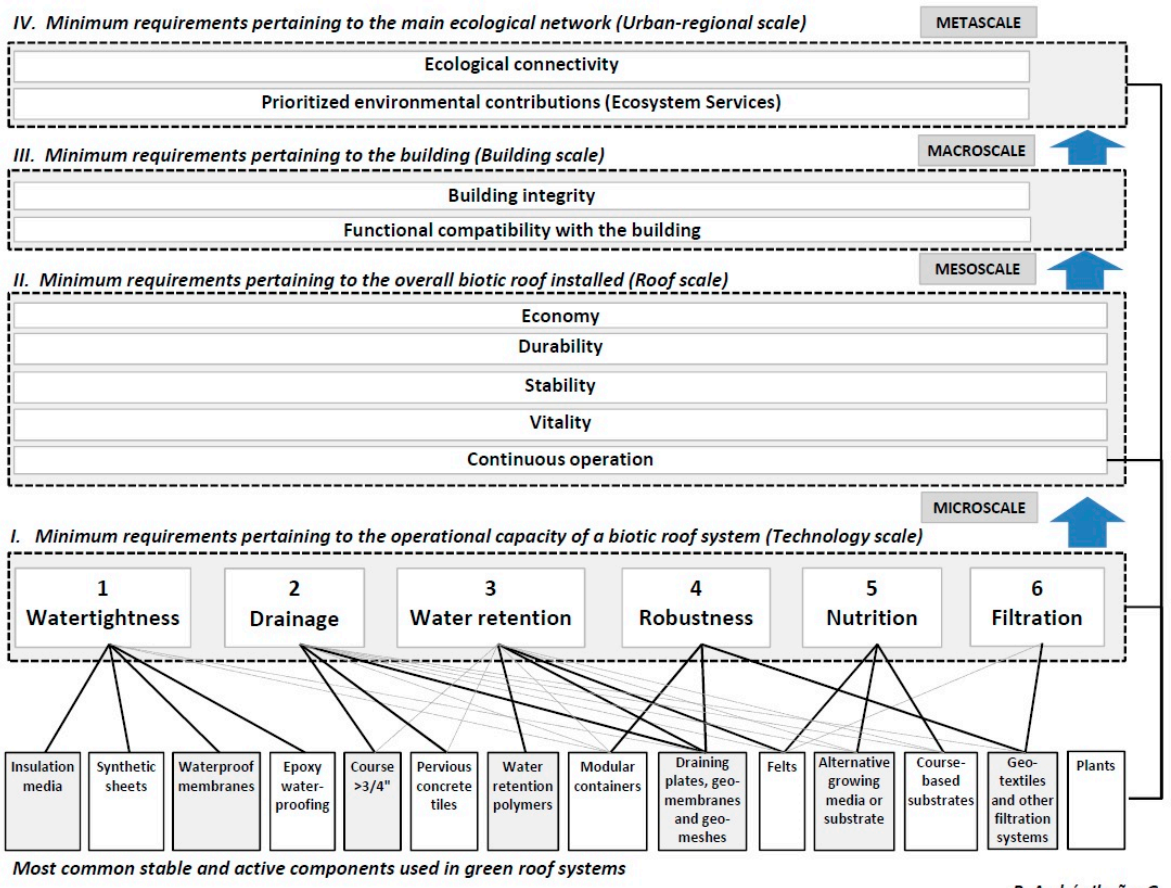

Figure 2. Main structure of the BBRG based on the key functional principles of green roofs at four scales: technology, roof, building, and city-region. The set of physical components that make up green roofs are shown in the lower part. The two middle levels of the meso- and metascales act as an interface between the physical forms of the microscale and the environmental aspirations of the metascale level on top.

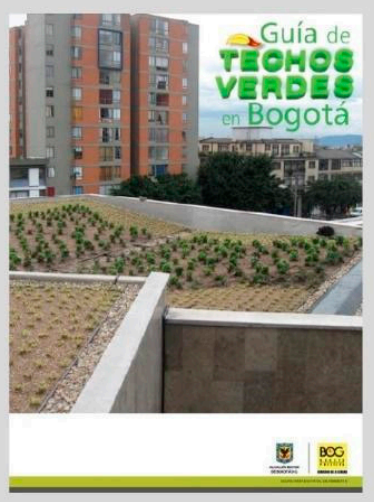

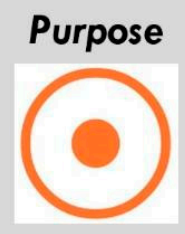
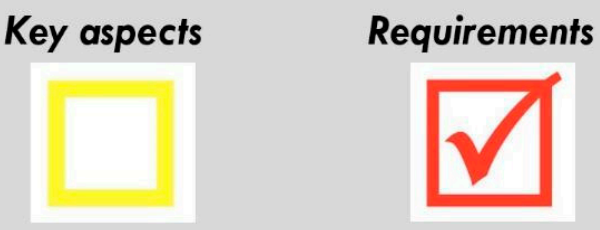

Properties and units

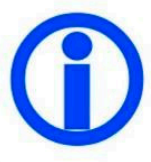

Recommendations

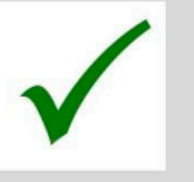

Figure 3. To facilitate navigation and understanding of the BBRG, five headings elaborate on each of the functional principles: purpose, key aspects, requirements, properties and units, and recommendations. For easy identification of each heading, an icon with a distinctive shape and color was developed.

\subsection{Multi-Scale Approach}

The multifunctional nature of green roofs has extensively been referred to in the literature. In fact, when authors elaborate on the advantages of this technology, they mention the multiple benefits that it brings, or the number of problems of different kinds and scales that it can simultaneously tackle $[3,6,8,9]$. Although several technical green roof documents refer to a specific performance related to different scales $[4-8,17,18,32]$, those contents are not structured or systematized in a way that 
facilitates a panoramic understanding of the overall cross-scale performance. This systematization is key so that different stakeholders and actors can find clear technical criteria according to the scale or scales which interest them. For example, the selection criteria of a specific component in the growing media of a green roof determine its draining capabilities at the microscale of the typical system section, but also generate implications and consequences for the flood risk of an overall neighborhood and the kind of flora and fauna the green roof attracts, which are both key aspects to be taken into account at the larger scale of the urban or regional levels. The BBRG developed criteria to determine the performance of green roofs at four scales: the microscale of the technology, the mesoscale of the overall roof intervention, the macroscale of the building, and the metascale of the city or region where the green roof is located (Figure 2).

In addition to the functional principles of the microscale presented in Section 3.1, the BBRG define operational performance criteria for the three remaining scales. At the mesoscale, they define the minimum requirements pertaining to the overall biotic roof installed: continuous operation, vitality, stability, durability, and economy. At the metascale, the BBRG establish the minimum requirements pertaining to the overall building undergoing the intervention: building integrity and functional compatibility. Finally, at the metascale, two performance criteria are addressed: ecological connectivity and prioritized environmental contributions or services (Figure 2). The contents of each functional principle at the meso-, macro- and metascales are also organized in the five headings explained before for user friendliness and understanding (Figure 3).

\subsection{Performance Scoping}

In terms of scope and outreach, the BBRG have three aims. The first one is ensuring the quality of the practice to foster acceptance and trust in the building industry. For this aim, the BBRG set the basic performance for compulsory compliance by establishing the minimum requirements to be achieved in the four scales presented in the previous section. The second aim is encouraging optimal best practices in the contractor's arena while creating added value for the building. To achieve this, the BBRG outline four aspects recommended for advanced performance: low weight, self-regulation and low maintenance, thermal insulation, and acoustic insulation. Finally, the BBRG aim to create a cornerstone for future incentives based on special performance for six aspects linked to urban environmental quality: evaporation rate, reduction of surface runoff, reduction of stormwater discharge rate, capture of greenhouse gases (GHGs), oxygen emission, and ecological restoration (Figure 4). Five stages of the lifecycle process are addressed: studies and design, preparation, installation, follow-up, and disassembly. 


\begin{tabular}{|c|c|c|c|}
\hline \multicolumn{4}{|c|}{ BOGOTA GREEN ROOF GUIDELINES } \\
\hline \multicolumn{4}{|c|}{3 PERFORMANCE SCOPES } \\
\hline & \multicolumn{3}{|c|}{ Technical performance for Green Roof application in Bogota } \\
\hline \multirow{15}{*}{$\begin{array}{c}\text { Basic Performance } \\
\text { For Compulsory Compliance }\end{array}$} & \multirow{6}{*}{$\begin{array}{l}\text { Minimum requirements pertaining to } \\
\text { the operational capacity of a biotic } \\
\text { roof system }\end{array}$} & & Watertightness \\
\hline & & 2 & Drainage \\
\hline & & & Water retention \\
\hline & & & Robustness \\
\hline & & & Nutrition \\
\hline & & 6 & Fitration \\
\hline & \multirow{5}{*}{$\begin{array}{l}\text { Minimum requirements pertaining to } \\
\text { the overall biotic roof installed }\end{array}$} & & Economy \\
\hline & & & Durability \\
\hline & & 9 & Stability \\
\hline & & & Vitality \\
\hline & & 11 & Continuous operation \\
\hline & \multirow{2}{*}{$\begin{array}{l}\text { Minimum requirements pertaining to } \\
\text { the building }\end{array}$} & 12 & Building integrity \\
\hline & & 13 & Functional compatibility with the building \\
\hline & \multirow{2}{*}{$\begin{array}{l}\text { Minimum requirements pertaining to } \\
\text { the main ecological network }\end{array}$} & 14 & Ecological connectivity \\
\hline & & 15 & Prioritized environmental contributions (E.S.) \\
\hline \multirow{4}{*}{$\begin{array}{l}\text { Advanced performance } \\
\text { recommended as best } \\
\text { practice }\end{array}$} & \multirow{4}{*}{ Advanced performance } & & Low weight \\
\hline & & & Self-regulation and low maintenance \\
\hline & & 3 & Thermal insulation \\
\hline & & & Acoustic insulation \\
\hline \multirow{6}{*}{$\begin{array}{l}\text { Special performace for } \\
\text { future incentives }\end{array}$} & \multirow{6}{*}{ Special performance } & & Evaporation rate \\
\hline & & 2 & Reduction of runoff water \\
\hline & & 3 & Reduction of discharge rate \\
\hline & & 4 & GHG capture \\
\hline & & & Oxygen emission \\
\hline & & 6 & Ecological restoration \\
\hline
\end{tabular}

Figure 4. General scope and outreach of the BBRG motivated by three aims: quality, optimal best practices, and future incentives.

\subsection{Definitions and Classification}

The BBRG refer to the widespread term "Green Roof" for the purpose of maintaining a unifying language. However, they encourage the use of the term "Biotic Roof" as a more accurate concept that best describes the actual nature of this type of practice, as it does not refer to the color aspect but it accounts for its actual functioning based on the integration of living material and natural habitat on roofs.

A biotic roof is a constructive system that enables a plant landscape to endure on the roof of a building by means of a functional integration of (1) the building, (2) specific vegetation, (3) manufactured growing media, and (4) climatic and environmental factors. This integration can be achieved via six basic functions: (1) watertightness, (2) drainage, (3) water retention, (4) robustness, (5) nutrition, and (6) filtration. Any piece of horizontal or inclined surface that covers a built space is considered a roof. This definition encompasses terraces, rooftops, flat roofs, pitched roofs, decks over interior spaces, and decks over basements.

\subsubsection{Biotic Roof Components}

The BBRG consider that all biotic roofs are composed of three types of components: (1) active components, (2) stable components, and (3) auxiliary elements. The success of a biotic roof depends on the right interaction of these components and the correct adaptation to a specific building (Figure 5a). 


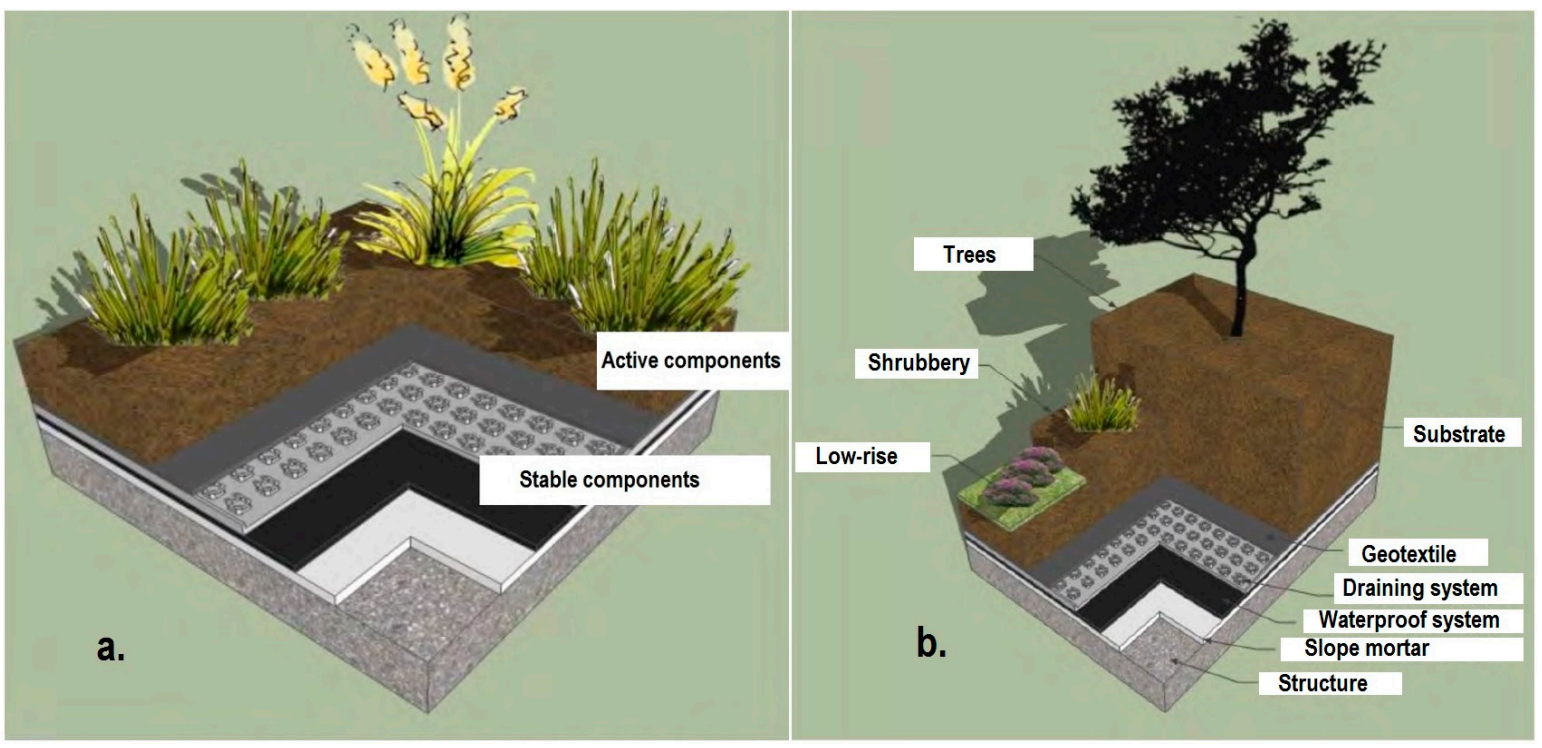

Figure 5. (a) BBRG's classification of components based on the stability of the chemical and physical state: active and stable components; (b) The weight and height of plants are key criteria for green roof taxonomy in the BBRG (light, moderate, and robust).

\section{Active components}

These components display constant physical and chemical changes to achieve their functions throughout the roof's lifecycle. They are biological elements or elements that support life in the system: plants or other living organisms and any form of growing media. The resilience of these components is determined by their capacity to successfully adapt to the environmental conditions and to the chemical and physical changes that take place in their interaction. The BBRG provide a catalogue of local plants that are adapted to Bogota's climate, ecological structure, and environmental conditions. The section on plants provides directions on how to select species considering the type of biotic roof, the microclimate determined by the particular location of the building, and the surrounding local biota that belong to the main ecological network of the city. The BBRG consider the growing media as the most critical component to warranty the success of the biotic roof, as it is the interface between the most active component (plants) and the inert ones. It supports vegetation life by providing nutrients, water, and physical anchorage. Alterations of the growing media are expected over the lifetime of a biotic roof; however, these changes must be kept within specific ranges provided by the BBRG.

Stable components

These are the inert components that must maintain chemical and physical stability to achieve their functions throughout the roof's lifecycle. Stable components are manufactured and are intended to fulfill specific performance parameters within the whole system: waterproofing layers, root barriers, filtration media and layers, pavement blocks, draining systems, etc. The durability of these components is determined by their capacity to successfully withstand changing environmental conditions, humidity, and harmful living agents like fungi and microorganisms.

Auxiliary elements

These elements are inert and stable components that perform specific functions to adapt and fix a typical section of a given biotic roof system to the structure of a building, namely, separation, edging, confining, protection, transit, lighting, etc.

\subsubsection{General Classification of Biotic Roofs in Bogota}

The most used classification of green roofs separates them into two categories: extensive and intensive. Although these types of green roofs were clearly defined in the FLL guidelines' [16], there are recent concerns related to the rising ambiguity derived from this classification. Several authors, 
contractors, guides, and manuals refer to fuzzy categories like "semi-extensive" or "semi-intensive", which dilute the fundamental purposes of identification and differentiation of a taxonomy system. This is partly due to the fact that the terms extensive and intensive do not necessarily communicate the purpose of the roof. In addition, the spontaneous emergence of suffixes like "semi" suggest that the taxonomy system should establish a subcategory that allows users to arrive at more specific typologies. Consequently, the BBRG classify biotic roofs according to two criteria: (1) the main purpose and the follow-up level (Figure 6) (primary classification), and (2) the degree of robustness, that is, the weight and vegetation height (complementary classification) (Figures 7-10).

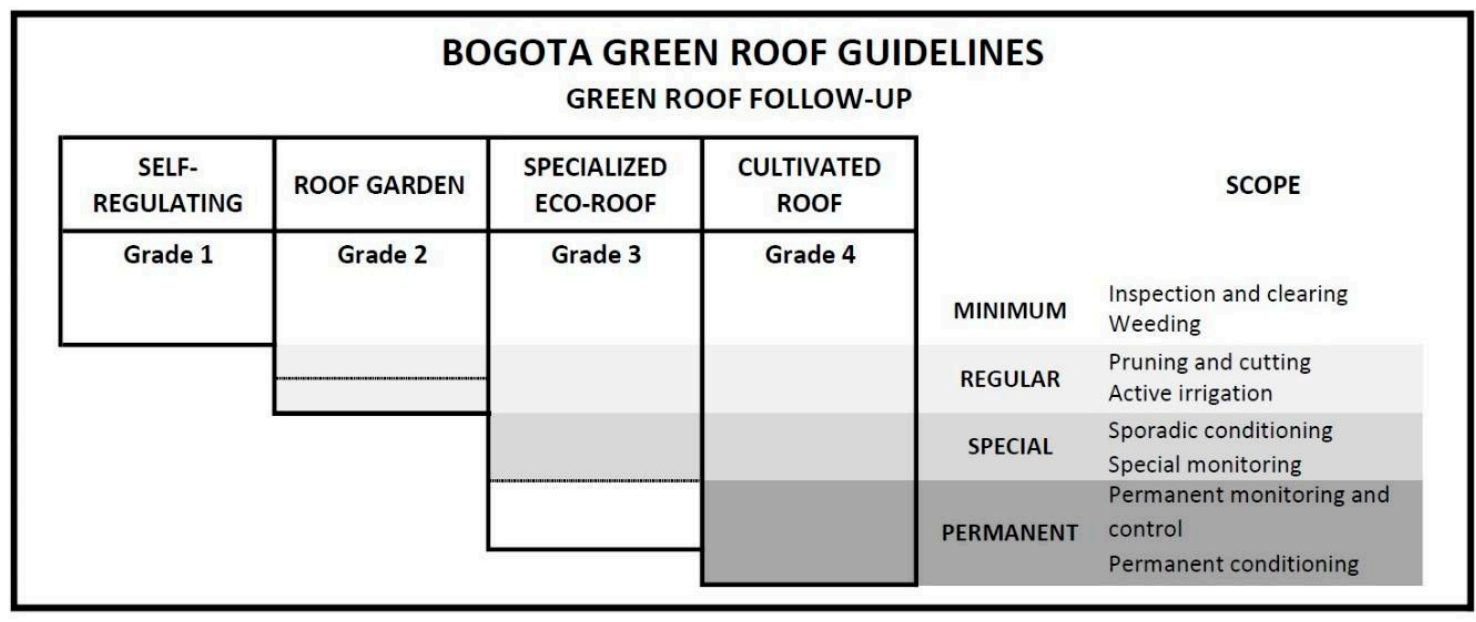

Figure 6. Different levels of green roof maintenance depending on the type and scope of follow-up activities. These levels and the four key purposes of the green roof facilitate primary classification in the BBRG.

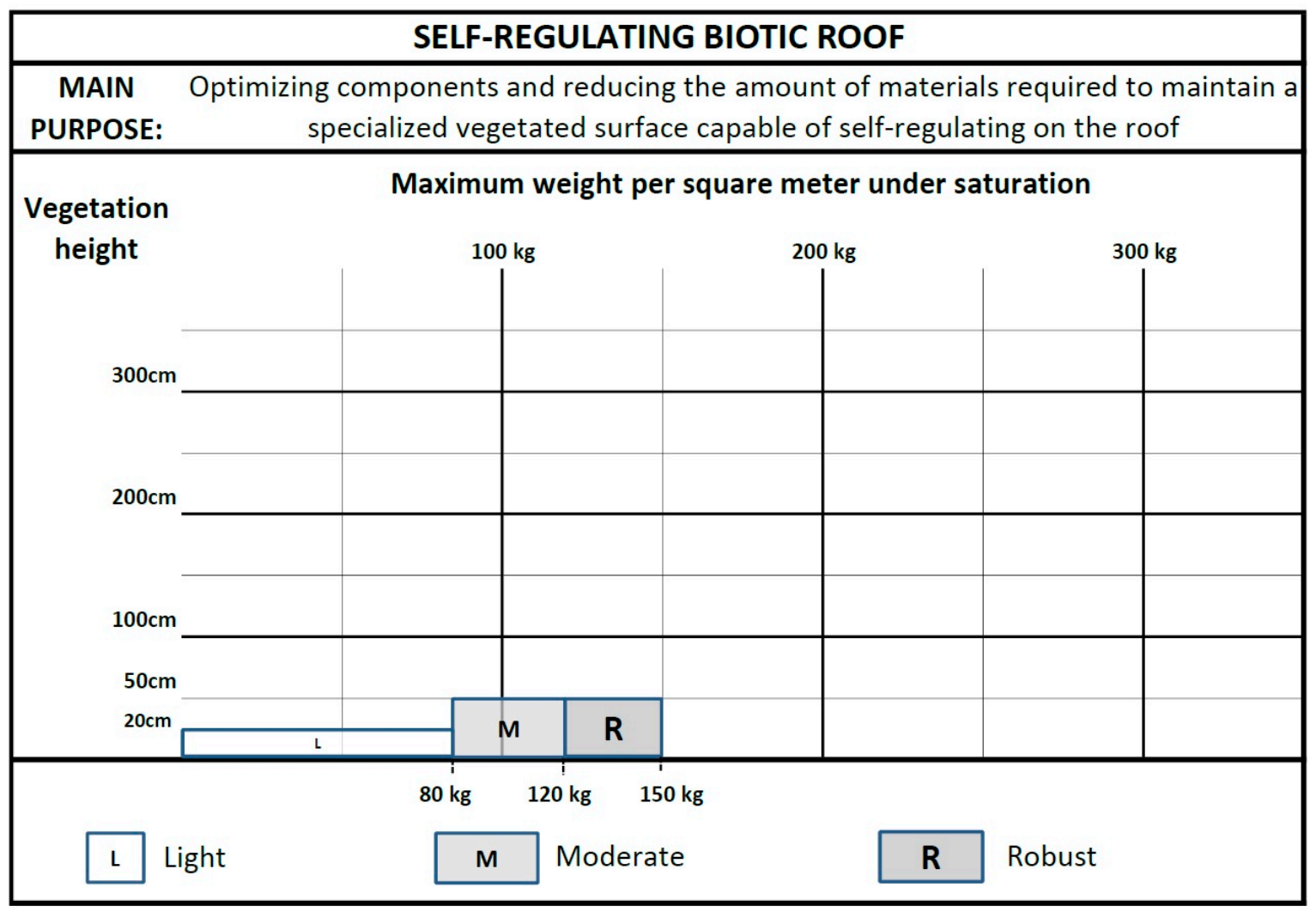

Figure 7. Levels of robustness of self-regulating biotic roofs determined by the vegetation height and the weight of the system under saturation conditions. 


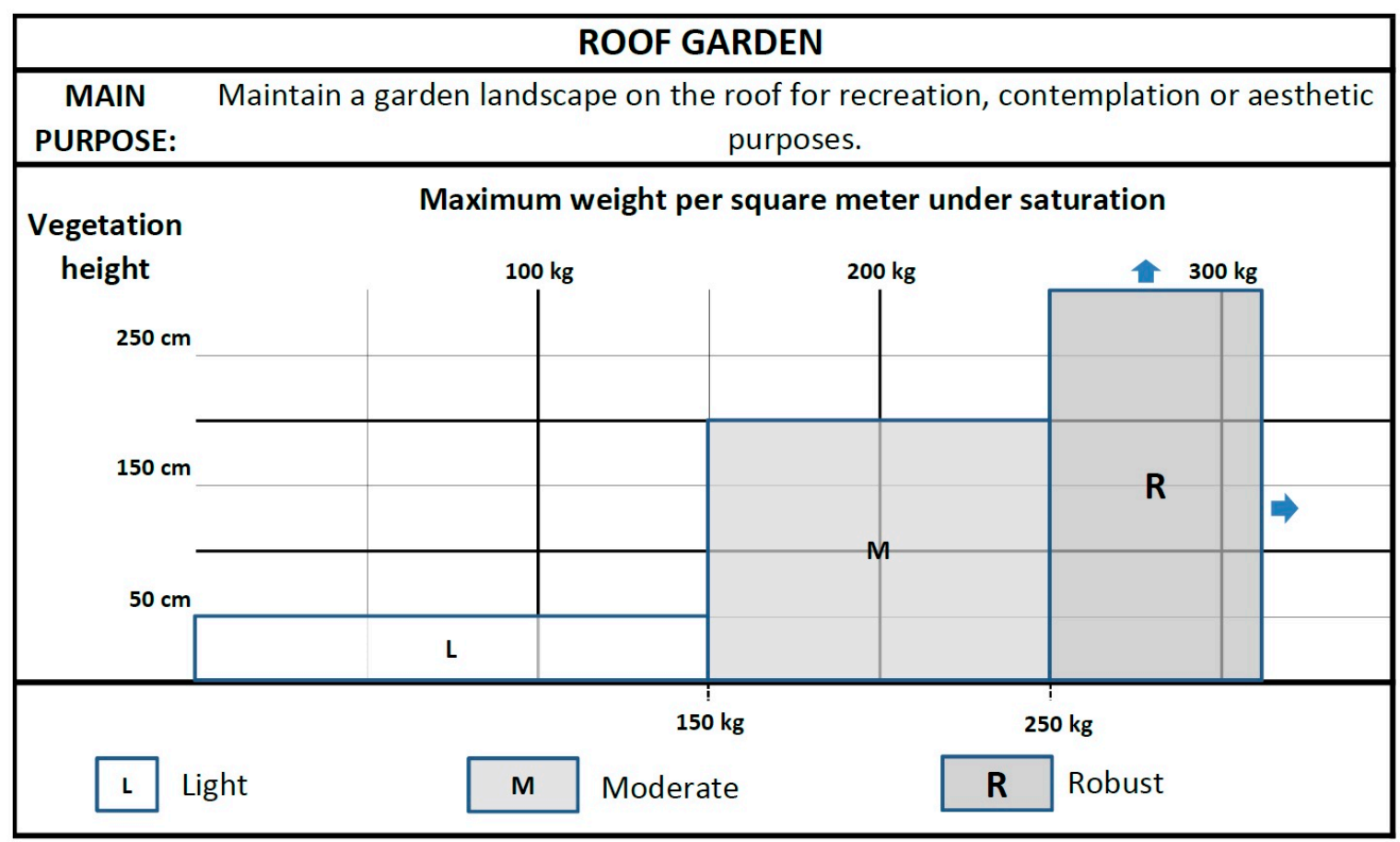

Figure 8. Levels of robustness of roof gardens determined by the vegetation height and the weight of the system under saturation conditions.

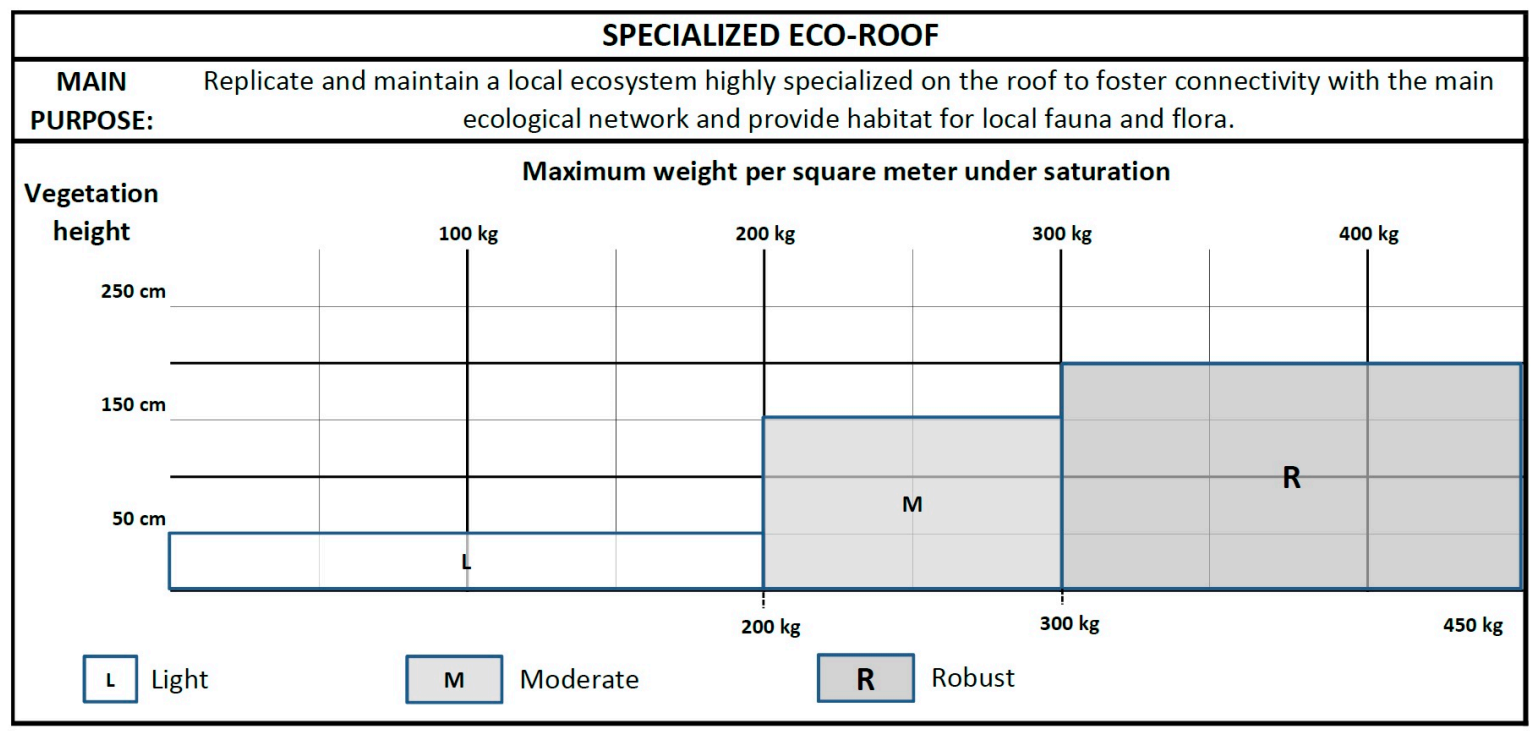

Figure 9. Levels of robustness of specialized eco-roofs determined by the vegetation height and the weight of the system under saturation conditions.

Typologies based on primary classification

Self-regulating roof

A biotic roof must provide the ideal physiological and technical conditions to maintain a healthy vegetation layer over a rooftop. A self-regulating roof reaches this goal using the minimum amount of materials as possible. Since this type of roof is not intended for transit, except for inspection and maintenance, it must be as light as possible to minimize structural loads. To ensure the vitality of vegetation with the minimum grade of follow-up protocol and without active irrigation systems, specialized plants must be low-growing and adapted to environmental stress and growing media with low contents of organic matter. Key features: self-regulation, resilience, low weight. 


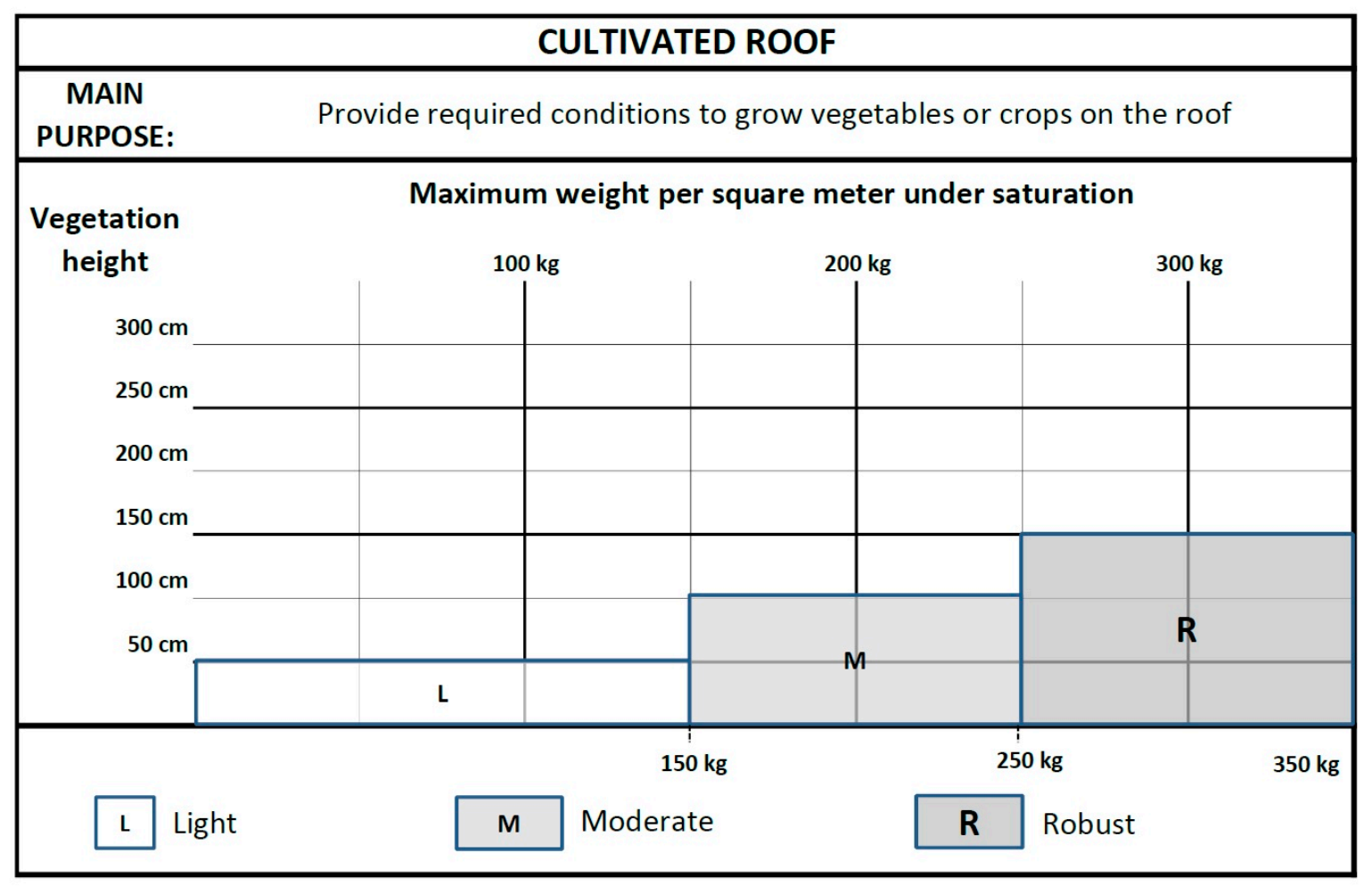

Figure 10. Levels of robustness of cultivated roofs determined by the vegetation height and the weight of the system under saturation conditions.

Roof garden

The main purpose of this type of roof is to create an accessible landscape on a rooftop for recreation or contemplation. To meet this purpose, vegetation is not restricted in height and must have aesthetic qualities. These systems are usually combined with paved surfaces, walking decks, a gravel course, furniture, and other auxiliary elements. Key features: accessibility, recreation, ornamental value.

Specialized eco-roof

The main purpose of a specialized eco-roof is to replicate and maintain over a rooftop an endemic ecosystem landscape to integrate the building into the main ecological network of the city, and to provide a habitat for the local flora and fauna. Key features: biodiversity, connectivity with local ecosystems.

Cultivated roof

The main purpose of a cultivated roof is agricultural production. To meet this purpose, circulation zones and corridors are differentiated from the plantation areas to facilitate planting, care, and harvesting. This type of green roof demands outstanding waterproofing performance given the higher exposure to damage by roots and physical wear caused by crop-related works. To maintain the environmental parameters required for productive plant production, back-up irrigation or storage systems must be used to ensure proper soil humidity and meet the water demand of crops, and environmental control techniques might be required (e.g., wind barriers, shading systems, storm water protection). Key features: plant production, environmental control, and active irrigation.

Sub-typologies based on complementary classification

Light

Light roofs meet all the minimum technical requirements and achieve the main purpose, while incorporating strategies to significantly reduce the overall load under saturation state.

Moderate

Moderate roofs use conventional techniques and components, which result in intermediate robustness. 
Robust

Robust roofs have the higher loads caused by heavier growing media needed to support higher vegetation, usually woody.

\section{Discussion}

The criteria of the main green roof guidelines reviewed are based on robust empirical studies, and their authors arrived at technical parameters after extensive research that took decades to be completed $[4,6,8,17,18]$. Scholars have argued that the most comprehensive document for green roof planning and design are the German FLL guidelines, as they have been highly successful in setting quality standards for green roof systems [17].

FLL guidelines set technical parameters for the layers of the most common green roof types. The focus on layers is also common in other guidelines [19-27] and academic research [5,6,8,17,18,33]. However, some scholars have called attention to performance and function as key dimensions of green roof policy making [6,17]. The BBRG have embraced this claim, which resulted in an inclusive approach that instead of favoring specific technologies or products, encourages operational capacity leading to better urban environmental quality.

Additionally, referenced guidelines not always respond to climatic conditions of non-temperate climates and to the informal institutional settings of developing countries and emerging markets going through initial stages of the regulation process, which makes it inadequate to import standards or guidelines without careful consideration. For the European context, Catalano et al. claimed that guidelines must be adapted to local contexts; they call for modifications suited to Mediterranean contexts [34]. Because the BBRG were socio-spatially designed, they correspond to specific local challenges and resources of Bogota, overcoming the "naïve conceptualization of space, scale and power" [35] (p. 15) of sustainability transition studies.

Another important issue is that unless cities manage to ensure good practices in the initial stages, green roof implementation will not make it to massive application stages due to lack of trust. Dvorak has highlighted the need to conduct more rigorous investigations to fill up the remaining technical gaps, in order to prevent failures and ensure the quality of application [18]. This is indeed a desirable solution, but often unfeasible in developing countries that must give priority to other issues like basic access to vital services and therefore do not channel the required budgets for the type of long-term studies required for a systematic definition of technical parameters in non-temperate climates.

Developing countries have complex and diverse socio-economic and socio-technical domains that range from informal settlements that rely on local appropriate solutions not produced by the manufacturing industry [36], to avant-garde buildings that follow a techno-rational mainstream approach. The challenge of embracing a wide technology spectrum was addressed by the dual spirit of the guidelines. They intended to be both prescriptive and suggestive. This offered niche actors the possibility to be included, independently from their technological development. Those who were lagging behind had a guide to learn from and catch up with, while the more technologically advanced actors could continue innovating.

Despite these barriers, megacities of developing countries need to urgently transition into substantive sustainable or ecoproductive models. Given the multifunctional nature of green roofs and other forms of infrastructure, and the multiple benefits associated with them, this practice is among the most effective ways to trigger positive incremental change in cities [3]. Thus, the role of local governments and participatory networks like non-governmental organizations (NGOs) in guiding multiple key actors through local guidelines is crucial to overcome barriers [29]. We support authors who argue that participatory guidelines contribute to acceptance, good perception, and awareness from various parties, and that they can encourage the niche growth in developing countries [37]. The BBRG compensate the lack of empirical data and scientific studies in the local Colombian context, with the participatory process as an alternative way to arrive at an empirical ground based on the experience 
of every actor and stakeholder. Nevertheless, it is important to mention that the document included quantitative data for some performance ranges based on local studies.

One of the greatest challenges is how to articulate green roof and other types of green infrastructure guidelines with the existing and future urban planning instruments suited to climate change and other sustainability challenges. The potential of green roofs to bridge the three main spatial structures of cities has been previously discussed [3], namely, main ecological network, socio-economic and spatial structure, and structures of functions and services. To facilitate the articulation of green roofs to the local urban guidelines, the BBRG address four scales (i.e., the green roof system itself, the overall roof, the building, and the city), allowing for a grounded system perspective to socio-ecological challenges of specific areas of Bogota, a highly unequal and high-altitude tropical city.

Finally, the guidelines described above present three features that we would like to point at in relation to niche structuration processes in the developing world. First, in general, the participatory process brought about important aspects that the guidelines should address, resulting in a contextualized policy document rather than a copy of the most influential guidelines. Second, because the BBRG are function-based rather than component-based, they make room for local technologies to emerge, giving autonomy to the niche. Third, the independence from imported technologies allows new visions and framings of innovation that are required to counteract patterns of social exclusion [38]. This opens up a wider spectrum of green roof technologies that can be applied in multiple socio-economic environments, including adaptations and local solutions with materials that are not necessarily produced by the local manufacturing industry. The autonomy promoted by the BBRG allows experimentation at different levels, bringing about new knowledge and developing capabilities for urban sustainability transitions [39].

\section{Conclusions}

This paper has documented the BBRG's formulation process. The distinctive features of these guidelines refer to the need for developing novel definitions of systems and components to provide a better technical ground. The guidelines' contents were structured according to five categories to facilitate readability by all stakeholders. These categories are purpose, key aspects, requirements, properties and units, and recommendations. The BBRG refer to commonly known green roof systems as biotic roofs. The guidelines classify biotic roof components into active and stable components and auxiliary elements. They propose a general composite taxonomy system, based on the main purpose of the biotic roof (e.g., self-regulation, garden, ecological restoration, cultivation) and its robustness (determined by the vegetation height and the system's weight). Additionally, the BBRG encompass the functions that should be ensured for desired performance at four different scales (i.e., technology, roof, building, and urban scales). In summary, the guidelines aim for quality, best practices, and incentives. In order to achieve this, the BBRG establish the minimum performance requirements, as well as for advanced performance and special performance.

This paper presented and discussed the formulation process of the BBRG as a stepping stone in the development of the green roof niche in Bogota. Their elaboration was based on a participatory process, which uncovered knowledge and technologies that fitted well the local context. The experience, knowledge, and constraints provided by multiple actors filled the gap of previous scientific evidence about the performance of green roof technologies in Bogota. Rather than blindly adapting foreign guidelines, an active discussion took place, embracing the insights offered by diverse actors. As a result, the BBRG suited a wide spectrum of local needs, taking into account the social, economic, and environmental peculiarities of this tropical megacity.

The process of developing the BBRG by following participatory processes offered insights about how the experience, knowledge, and constraints provided by multiple actors are key to developing guidelines suited to a wide spectrum of local needs, in the absence of robust scientific or empirical certainties about the performance of green roof technologies in complex and diverse climate zones. 
Additionally, we found that the participatory definition of terminology, fundamental principles, taxonomy, and sustainability-related concepts was key to promoting and strengthening practices among the niche community. The technological autonomy gained throughout this process empowered niche actors and promoted local green infrastructure innovations. Therefore, the BBRG illustrate a case of niche "empowering and transformation" rather than "fitting and conforming", which is necessary for sustainability transitions [12]. The guidelines fostered positive urban incremental change that increases the rate at which environmental contributions are generated, following a stewardship approach that arises from the interplay of diverse local actors.

The distinctive aspects of the BBRG imply further research and advancement on several fronts. Even though the practical consequences in the market were not discussed in the paper because they were beyond its scope, we acknowledge the need of a BBRG impact assessment. Additionally, further studies are needed to determine the incidence of inclusive approaches like the one taken by the BBRG on the number of green roof implementations in comparison to similar settings that follow a more traditional approach, or that have a compulsory law on green roofs in the region (as in the case of Cordoba, Argentina).

Second, there is a need to conduct further extensive studies in particular contexts of Bogota, to refine the ranges of parameters provided and define aspects that are outlined but not quantified, especially at the metascale. The development of methods to assess the value of environmental contributions delivered by a green roof and the criteria needed to determine its contributions to the ecological connectivity of the local ecosystems, based on more robust databases of fauna and flora, are examples for such studies.

Further research may address new incentive schemes based on private-public actor co-benefits resulting from the special performance of green roofs. In the case of Bogota, there is a need to develop non-monetary, space-oriented trade-off incentives that create a win-win situation. For example, a builder that reduces the flood risk and urban heat island effect via a green roof in a particular area could be granted a higher footprint index proportional to the public contribution generated.

Author Contributions: Conceptualization, R.A.I.G and M.R.-M; methodology, R.A.I.G; writing-original draft preparation, R.A.I.G and M.R.-M; writing-review and editing, R.A.I.G and M.R.-M; project administration, R.A.I.G.

Funding: This research received no external funding

Conflicts of Interest: The authors declare no conflict of interest.

\section{References}

1. UN Urbanization Statistics. 2018 Revision of World Urbanization Prospects. 2018. Available online: https://esa.un.org/unpd/wup/; https://www.un.org/development/desa/publications/2018-revision-of-worldurbanization-prospects.html (accessed on 2 May 2019).

2. Bergesen, J.D.; Suh, S.; Baynes, T.M.; Musango, J.M. Environmental and natural resource implications of sustainable urban infrastructure systems. Environ. Res. Lett. 2017, 12, 125009. [CrossRef]

3. Ibáñez Gutiérrez, R.A. Biotectonics and positive incremental change: Embracing the new Eco-urban. In Green Cities in the World, 2nd ed.; Briz, J., Köhler, M., de Felipe, I., Eds.; Editorial Agricola Espanola, S.A.: Madrid, Spain, 2015; pp. 175-191.

4. Carter, T.; Fowler, L. Establishing green roof infrastructure through environmental policy instruments. Environ. Manag. 2008, 42, 151-164. [CrossRef] [PubMed]

5. Getter, K.L.; Rowe, D.B. The role of extensive green roofs in sustainable development. Hortscience 2006, 41, 1276-1285. [CrossRef]

6. Oberndorfer, E.; Lundholm, J.; Bass, B.; Coffman, R.R.; Doshi, H.; Dunnett, N.; Gaffin, S.; Köhler, M.; Liu, K.K.Y.; Rowe, B. Green Roofs as Urban Ecosystems: Ecological Structures, Functions, and Services. BioScience 2007, 57, 823-833. [CrossRef]

7. Li, W.C.; Yeung, K.K.A. A comprehensive study of green roof performance from environmental perspective. Int. J. Sustain. Built Environ. 2014, 3, 127-134. [CrossRef] 
8. Shafique, M.; Kim, R.; Rafiq, M. Green roof benefits, opportunities and challenges-A review. Renew. Sustain. Energy Rev. 2018, 90, 757-773. [CrossRef]

9. Teotónio, I.; Silva, C.M.; Cruz, C.O. Eco-solutions for urban environments regeneration: The economic value of green roofs. J. Clean. Prod. 2018, 199, 121-135. [CrossRef]

10. Ramos-Mejía, M.; Franco-Garcia, M.L.; Jauregui-Becker, J.M. Sustainability transitions in the developing world: Challenges of socio-technical transformations unfolding in contexts of poverty. Environ. Sci. Policy 2018, 84, 217-223. [CrossRef]

11. Kemp, R.; Schot, J.; Hoogma, R. Regime shifts to sustainability through processes of niche formation: The approach of strategic niche management. Technol. Anal. Strateg. Manag. 1998, 10, 175-196. [CrossRef]

12. Smith, A.; Raven, R. What is protective space? Reconsidering niches in transitions to sustainability. Res. Policy 2012, 41, 1025-1103. [CrossRef]

13. Grin, J.; Rotmans, J.; Schot, J. Transitions to Sustainable Development. New Directions in the Study of Long Term Transformative Change; Routledge: New York, NY, USA; London, UK, 2010.

14. Ibáñez Gutiérrez, R.A.; Cardenas, M. Guía Técnica de Techos Verdes de Bogotá; Environment of Bogota: Bogota, Colombia, 2011.

15. Berkhout, F.; Verbong, G.; Wieczorek, A.J.; Raven, R.; Lebel, L.; Bai, X. Sustainability experiments in Asia: Innovations shaping alternative development pathways? Environ. Sci. Policy 2010, 13, 261-271. [CrossRef]

16. Forschungsgesellschaft Landschaftsentwicklung Landschaftsbau. Guideline for the Planning, Execution and Upkeep. of Green-Roof Site; Forschungsgesellschaft Landschaftsentwicklung Landschaftsbau: Bonn, Germany, 2002; p. 95.

17. Hui, S.C.M. Development of technical guidelines for green roof systems in Hong Kong. In Proceedings of the Joint Symposium 2010 on Low Carbon High Performance Buildings, Hong Kong, China, 23 November 2010.

18. Dvorak, B. Comparative Analysis of Green Roof Guidelines and Standards in Europe and North America. J. Green Build. 2011, 6, 170-191. [CrossRef]

19. American National Standards Institute; Single Ply Roofing Industry. Green Roofs for Healthy Cities, Wind Design Standard for Vegetative Roofing Systems. In ANSI/SPRI RP-14; Single Ply Roofing Industry: Waltham, MA, USA, 2010; p. 36.

20. ASTM International. Standard Practice for Determination of Dead Loads and Live Loads Associated with Green Roof Systems; ASTM International: West Conshohocken, PA, USA, 2005; Volume 2397-05, p. 4.

21. ASTM International. Standard Test Method for Maximum Media Density for Dead Load Analysis of Green Roof Systems; ASTM International: West Conshohocken, PA, USA, 2005; Volume E2399-05, p. 4.

22. ASTM International. Standard Test Method for Saturated Water Permeability of Granular Drainage Media [Falling-Head Method] for Green Roof Systems; ASTM International: West Conshohocken, PA, USA, 2005; Volume E2396-05, p. 3.

23. ASTM International. Standard Test Method for Water Capture and Media Retention of Geocomposite Drain Layers for Green Roof Systems; ASTM International: West Conshohocken, PA, USA, 2005; Volume E2398-05, p. 3.

24. ASTM International. Standard Guide for Selection, Installation, and Maintenance of Plants for Green Roof Systems; ASTM International: West Conshohocken, PA, USA, 2006; Volume E2400-06, p. 4.

25. Green Roof Organization. The GRO Green Roof Code. In Green Roof Code of Best Practice for the UK 2011; Groundwork Sheffield: Sheffield, UK, 2011; p. 26.

26. Secretaría del Medio Ambiente del Distrito Federal. Norma ambiental para el Distrito Federal NADF-013-RNAT-2007, que establece las especificaciones técnicas para la instalación de sistemas de naturación en el Distrito Federal. In NADF-013-RNAT-2007; del Medio, S., del Distrito Federal, A., Eds.; Gaceta Oficial Del Distrito Federal: Mexico City, Mexico, 2008; pp. 12-36.

27. Toronto City Council. Green Roof Bylaw 583-2009; Green Roof Construction Standard; Toronto City Council: Toronto, ON, Canada, 2009; pp. 1-17.

28. Irga, P.J.; Braun, J.T.; Douglas, A.N.J.; Pettit, T.; Fujiwara, S.; Burchett, M.D.; Torpy, F.R. The distribution of green walls and green roofs throughout Australia: Do policy instruments influence the frequency of projects? Urban For. Urban Green. 2017, 24, 164-174. [CrossRef]

29. Chen, X.; Shuai, C.; Chen, Z.; Zhang, Y. What are the root causes hindering the implementation of green roofs in urban China? Sci. Total Environ. 2019, 654, 742-750. [CrossRef] [PubMed] 
30. Acevedo Romero, J.C. Apoyo en la actualización del inventario e indicadores de techos verdes y jardines verticales y establecimiento de parcelas demostrativas para evaluar la adaptabilidad de especies como coberturas en este tipo de tecnologías en la ciudad de Bogotá. Informe Técnico de Pasantía. Alcaldía Mayor de Bogotá -Secretaría Distrital Ambiente. Available online: https://www.google.com/url?sa=t\&rct=j\&q=\&esrc= s\&source=web\&cd=1\&ved=2ahUKEwj-4pyi1fPiAhXCtlkKHcSECxcQFjAAegQIAxAC\&url=http $\% 3 \mathrm{~A} \%$ 2F\%2Frepository.udistrital.edu.co\%2Fbitstream\%2F11349\%2F13785\%2F1\%2FInventario \%2520Techos\% 2520Verdes\%2520y\%2520Jardines\%2520Verticales.pdf\&usg=AOvVaw36wj5-UiY7dCqN_N2RaVTf (accessed on 14 June 2019).

31. Ibáñez Gutiérrez, R.A. Ecoproductive architecture for multifunctional and restorative cities: From physical forms to environmental contributions. In Multifunctional Urban Green Infrastructure; Briz, J., Köhler, M., de Felipe, I., Eds.; Editorial Agricola Espanola S.A.: Madrid, Spain, 2019; pp. 175-200.

32. University of Colorado Denver. Design Guidelines for Green Roofs; University of Colorado Denver: Denver, CO, USA, 2003.

33. Carvajal Muñoz, J.S.; Carmona García, C.E. Global research trends in green roofs: Benefits, main developments and future needs. Producción + Limpia 2015, 10, 173-185. [CrossRef]

34. Catalano, C.; Laudicina, V.A.; Badalucco, L.; Guarino, R. Some European green roof norms and guidelines through the lens of biodiversity: Do ecoregions and plant traits also matter? Ecol. Eng. 2018, 115, 15-26. [CrossRef]

35. Truffer, B.; Coenen, I. Environmental innovations and sustainability transitions in regional studies. Reg. Stud. 2012, 46, 1-21. [CrossRef]

36. Forero, C.; Gutierrez, D.; Ibáñez Gutiérrez, R.A. Agricultura en territorios urbanos: Bogota region, Colombia. In Agricultura Urbana Integral: Ornamentaly Alimentaria, Una Visión Global e Internacional, 2nd ed.; Briz, J., de Felipe, I., Eds.; Editorial Agricola Espanola S.A.: Madrid, Spain, 2015; pp. 357-367.

37. Ismail, W.Z.W.; Abdullah, M.N.; Hashim, H.; Rani, W.S.W. An overview of green roof development in Malaysia and a way forward. AIP Conf. Proc. 2018, 2016, 020058.

38. Fressoli, M.; Around, E.; Abrol, D.; Smith, A.; Ely, A.; Dias, R. When grassroots innovation movements encounter mainstream institutions: Implications for models of inclusive innovation. Innov. Dev. 2014, 4, 277-292. [CrossRef]

39. Frantzeskaki, N.; Castán Broto, V.; Loorbach, D.; Coenen, I. Urban Sustainability Transitions; Routledge: New York, NY, USA, 2017. 